\title{
DIÁLOGOS: UMA LEITURA INTRATEXTUAL DE "VARANDAS DA EVA" (A CIDADE ILHADA) COM CINZAS DO NORTE E ÓRF ÃOS DO ELDORADO, DE MILTON HATOUM.
}

\section{DIALOGUES: A INTRATEXTUAL READING OF " VARANDAS DA EVA" (A CIDADE ILHADA) WITH "CINZAS DO NORTE" AND "ORFÃOS DO ELDORADO", OF MILTON HATOUM.}

\author{
Francisca Andréa Ribeiro da SILVA ${ }^{1}$ \\ Sylvia Maria TRUSEN ${ }^{2}$
}

\begin{abstract}
RESUMO: Este estudo pretende discutir as possíveis relações intratextuais entre o conto "Varandas da Eva" (A cidade ilhada) e as obras Cinzas do Norte e Órfãos do Eldorado. O foco incidirá no diálogo entre personagens do romance e da novela e as do conto, bem como na temática comum, especialmente no que concerne ao trabalho da memória e do tempo, como elementos primordiais na narrativa. Outrossim, destacar-se-ão as personagens femininas presentes em ambas, observando o caráter enigmático que as enlaça.
\end{abstract}

Palavras-chave: Intratextualidade. Feminino. Memória.

\begin{abstract}
This study discusses the possible intratextual relations between the story " Varandas da Eva" ( A cidade ilhada), "Cinzas do norte" and "Órfãos do Eldorado". The focus will be on dialogue between characters in the romance and the novel and the short story, in the common theme, especially with regard to the work of memory and time, as key elements in the narrative. Also, will stand out - the female characters present in both , watching the enigmatic character that entangles
\end{abstract}

Keywords: Intratextuality. Female. Memory.

\section{Introdução}

A obra do escritor amazonense Milton Hatoum tem conquistado leitores nacionais e internacionais e despertado na crítica literária grande interesse de análise, além ter alcançado um número considerável de prêmios, demonstrando, assim, o reconhecimento da qualidade literária da produção do escritor.

Amante de uma linguagem simples, objetiva, muito mais narrativa do que descritiva, Milton Hatoum retrata, em suas obras, na maioria das vezes, dramas familiares, ambientados na Amazônia, especificamente em Manaus e seus arredores. Apesar do lugar das narrativas ser o mesmo - a região amazônica - o autor foge ao estereótipo de escritor regionalista, pois não é sua pretensão descrever a

\footnotetext{
${ }^{1}$ Mestranda do Programa de Pós-Graduação em Linguagens e Saberes na Amazônia, Universidade Federal do Pará. : andrearibsilva@hotmail.com

${ }^{2}$ Profa. Dra. do Programa de Pós-Graduação em Linguagens e Saberes na Amazônia, Universidade Federal do Pará. Orientadora. sylviatrusen63@gmail.com
} 
Amazônia sob olhares românticos, que tendem a engrandecer a região, enaltecendo suas belezas regionais. Pelo contrário, a sua ficção representa a Manaus em decadência, derruindo após a ascensão e decadência do ciclo da borracha. Assim é que lemos em romances como Órfãos do Eldorado a decadência de personagens que representam a elite manauense em consonância com a situação de degradação da região, outrora rica sob o influxo da borracha.

Outros fatores que contribuem para a qualidade da obra hatouniana é que inseridos nos dramas familiares surgem questões universais, como os amores impossíveis, o ciúme e a inveja, a rivalidade entre irmãos, a diversidade religiosa e cultural, além de problemas nacionais, como a desigualdade social, a disparidade entre empregados e patrões, as relações entre imigrantes e nativos. Outrossim, o tempo e a memória constituem aspectos centrais da sua obra, de tal forma que ordenam e guiam a narração de romances como Relato de um certo oriente e Cinzas do Norte, ou da novela, Órfãos do Eldorado, por intermédio de analepses e prolepses. O procedimento, gerando anacronias, constantes idas-e-vindas no enredo, requer atenção especial do leitor, para não correr o risco de se perder na compreensão da narrativa, pois cada detalhe narrado é peça importante na tessitura do enredo. Benedito Nunes ressalta que a narrativa literária moderna, ao fazer uso da anacronia “[...] desenvolve-se na ordem inversa à cronológica, deixando em aberto sequências posteriormente completadas num movimento para trás, à semelhança do procedimento usado por Joseph Conrad em Nostromo. [...]” (NUNES, 1995, p. 32). Milton Hatoum, assim, articula as suas narrativas, e o leitor, em contato com elas, sente-se peça fundamental na relação receptiva, já que é necessário que ele vá articulando as informações da narrativa, como em um quebra-cabeças, montando, desse modo, a sua compreensão da obra.

Outro aspecto a se destacar é quanto à relação intratextual estabelecida entre os romances Cinzas do Norte, a novela Órfãos do Eldorado e o conto "Varandas da Eva" (A cidade ilhada). Sendo assim, propomos atentar neste artigo para o diálogo entre personagens, narradores, bem como para a temática comum entre essas três obras.

A trama do romance Cinzas do Norte ocorre entre os anos de 1950 a 1980 e tem como principal palco a cidade de Manaus. O enredo é contado a partir da relação entre as famílias de Lavo - o narrador que perdeu os pais ainda pequeno e foi criado pelos tios Ranulfo e Ramira - e de Mundo - personagem principal, filho de Alícia e Trajano Mattoso. O enredo envolve relações de amizade, de adultério, decadência financeira, desigualdade social, patriarcalismo, entre outros. Na novela, Órfãos do Eldorado, o protagonista principal é Arminto Cordovil, que recorda e conta seu drama pessoal a um interlocutor anônimo. A narrativa é conduzida, portanto, em primeira pessoa. Arminto Cordovil, filho de Amanto e neto de Edílio, pertence à linhagem que assistiu a glória e decadência da Belle Époque manauense. Descendendo de rico empresário do ramo da navegação de cargueiros, escava na memória a Manaus que "tinha tudo: luz elétrica, telefone, jornais, cinema, teatro, ópera" (HATOUM, 2008, p. 17) a mesma e 
simultaneamente outra que "fervilhava de comerciantes, peixeiros, carvoeiros, carregadores, marreteiros" (Ibdem, p. 19). A história narrada por analepse percorre a sorte trágica do narradorpersonagem, concentrando igualmente elementos diversos que vão da lenda da fundação de Manoa - o lugar confundido pelos colonizadores com a Eldorado - à glória da Manaus sob o influxo da borracha e seu posterior declínio. Órfão de mãe, foi criado sob a hostilidade do pai e dos cuidados de Florita - a empregada da casa. Arminto não correspondeu aos anseios paternos, que objetivara vê-lo formado em Direito e cuidando das finanças de sua empresa e envolveu-se com a misteriosa Dinaura, uma das internas do Sagrado Coração de Jesus, que sumindo desespera Arminto, que passa então a viver perseguindo a lembrança fantasmática da jovem. O enredo traz associações entre lendas e realidade, além também de assuntos voltados à decadência financeira e pessoal.

O conto "Varandas da Eva", por sua vez, aborda a temática da prostituição. Neste relato, o narrador se envolve, a partir de uma única noite passada em companhia de uma prostituta inominada, lançando-o em paixão arrebatadora, seguida, todavia, por decepção.

É tendo, portanto, em vista esses possíveis diálogos, entre os romances citados acima e o conto "Varandas da Eva", que faremos a análise seguinte.

\section{Possíveis diálogos}

Todo texto, de forma mínima ou não, apresenta uma relação intertextual com outros textos, seja, no discurso, na estrutura ou em outros elementos textuais: "O texto é sempre, sob modalidades várias, um intercâmbio discursivo, uma tessitura polifônica na qual confluem, se entrecruzam, se metamorfoseiam, se corroboram ou se contestam outros textos, outras vozes e outras consciências" (AGUIAR e SILVA, 2011, p. 625. Grifo do autor). Nesse sentido, o texto literário participa de uma memória do sistema literário, espécie de "contexto vertical do texto literário, um contexto entretecido de múltiplos e, por vezes, difusos nexos que se afundam na espessura do tempo [...]” (Ibidem, p. 264. Grifo do autor). Se esta remissão à memória do sistema literário é própria da literatura, de modo geral, no caso de Hatoum, ela parece desempenhar um papel particular. Efetivamente, ao leitor atento à sua obra não passarão despercebidas relações não apenas intertextuais, isto é, a outras obras da literatura, mas ao próprio conjunto da obra do autor - no campo da intratextualidade-, como procuraremos destacar neste trabalho. Dessa forma, ao vislumbrarmos o conto "Varandas da Eva", o romance Cinzas do Norte e a novela Órfãos do Eldorado, observamos uma relação intratextual, pois notamos personagens de mesmo nome que possuem, ademais, traços em comum. Assim, notamos que entre a personagem Dinaura (Órfãos do Eldorado) e a prostituta sem-nome do conto "Varandas da Eva" há semelhanças. Outrossim, cumpre assinalar, o discurso memorialístico é aspecto que atravessa o conjunto das obras do escritor. 
No conto "Varandas da Eva" da obra A cidade ilhada, o narrador comparece como sobrinho de Ranulfo, assim como ocorre com o narrador da obra Cinzas do Norte. Em "Varandas da Eva", Ranulfo, ou tio Ran, é descrito como um homem que ia com frequência ao prostíbulo. Porém, para Ranulfo já não era novidade, ao ponto de não se entusiasmar com isso: "Invejávamos tio Ran, que até se enjoara de tantas noites dormidas no Varandas. A vida, para ele, dava outros sinais, descaía para outros caminhos. Enfastiado, sem graça, o queijo erguido, ele mal sorria [...]" (HATOUM, 2014, p. 7). Percebemos, também, que, na visão do narrador, Ranulfo era homem que cumpria o que prometia, generoso para com o narrador e seus amigos, "Tio Ran, homem de palavra, foi generoso: espichou dinheiro para a entrada e a bebida. Depois tirou um maço de cédulas da carteira. Disse: isso é para as mulheres. E nada de molecagem. Cada um de vocês deve ser um gentleman com aquelas princesas” (Ibidem, p. 8). Assim, diante do exposto acima, podemos dizer que no conto uma de suas principais características é ser boêmio.

O personagem Ranulfo, em Cinzas do Norte, é também traçado como um homem que frequenta noite:

\begin{abstract}
Nossa casa na Vila da Ópera nunca ficou em ordem: o trabalho da costureira multiplicava panos, retalhos e moldes, e, vez ou outra, tio Ran levava para lá Corel e Chiquilito, dois amigos que começavam a fumar e beber antes da caldeirada de sábado; acabavam dormindo no assoalho, perto da porta aberta para a servidão, pois Ramira os proibia de pisar na saleta de costura; na manhã de domingo acordávamos com os discursos de um e outro, que defendiam ideias amalucadas sobre uma revolução no Brasil. Os assuntos eram variados e cruzados: reforma agrária, pesca de tambaqui, festa a bordo de um navio, o mais novo prostíbulo de Manaus, o Varandas da Eva. Brindavam ao Varandas, e Corel, com a bagana apagada na boca, gritava, animado: "O Rosa de Maio ainda é o melhor!". Tinham esquecido a revolução e a reforma agrária, e recordavam as noites da juventude no Rosa de Maio, Lá Hoje, Shangri-lá. Iam embora quando nem mesmo eles se reconheciam, deixando no chão um monte de pontas de cigarro e palitos de fósforos, copos com bebidas misturadas e um azedume que impregnava a saleta até a faxina seguinte. $O$ resto do domingo se arrastava, a casa ficava tão enfadonha que eu e minha tia íamos passear no balneário Quinze de Novembro. Ela aturava a esbórnia porque o irmão, desde a morte do meu pai, se tornara o "homem da casa". (HATOUM, 2010, p. 16-17)
\end{abstract}

A partir desse trecho podemos notar a semelhança entre os personagens Ranulfo, de Cinzas do Norte, e o Tio Ran de "Varandas da Eva", considerando o modo de vida adotado por ambos. Ademais, há de ressaltarmos a presença do nome do prostíbulo.

Contudo, é importante recordarmos que no romance Cinzas do Norte, Ranulfo é homem que não trabalha, ex locutor radiofônico. Já em "Varandas da Eva”, a personagem homônima, aparenta melhores condições materiais: possui um carro cobiçado - um Dauphine, recorda o sobrinho, espécie de narradortestemunha - além de financiar a noite de boemia dos jovens rapazes.

Outro aspecto que enlaça personagens dessas duas obras é a presença do personagem Minotauro em ambas. Em Varandas da Eva, Minotauro é descrito como um jovem rapaz de corpo grande e forte e com aspecto intimidador, por ser afoito e destemido: 
Minotauro, fortaço e afoito, quis ir antes. Foi barrado no portão alto, cuspiu na terra, deu meia-volta, quase marchando para trás. Era um destemido, o corpo grandalhão, e um jeito de encarar os outros com olho quente, de meter medo e intimidar. Mas a voz ainda hesitava: era aguda e grossa, de periquito rouco, e o rosto de moleque, assombrado, meio leso. (HATOUM, 2014, p. 7)

Tempos depois, Minotauro tornou-se soldado: “[...] Servia na base terrestre, de guerras na selva. [...]" (Ibidem, p. 11). E nesse momento da narrativa, é retratado como alguém que se orgulha do que faz: "Falava com desembaraço, cheio de si, alisando com os dedos grossos a boina azul. O rosto continuava assombrado, quase feroz, e a risada saía que nem uivo. [...]" (Ibidem). O narrador revela não sentir afinidade da maneira de pensar do amigo ou ex-amigo: “[...] Minotauro, já era meu ex-amigo? Está em outro mundo, nossos pensamentos não se encontram. [...]” (Ibidem, loc. cit.) e ainda acrescentou que não sabe se sentiu por ele pena ou raiva, reconhecendo que talvez tenha sentido desprezo.

Notamos que em Cinzas do Norte, o personagem Minotauro também é caracterizado como um jovem de corpo grande, violento e arrogante que amedrontava os colegas de escola:

\footnotetext{
Minotauro, corpanzil de cabeça pequena, ia pelejar por uma vaga no Departamento Estadual de Segurança Pública. Em dezembro de 1969, na despedida dos veteranos, ele se exibiu na arena do ginásio, violento e arrogante, esmurrando os calouros, obrigandoos a engolir terra e chumaços de capim cheios de formigas. (HATOUM, 2010, p. 70)
}

Outra descrição de Minotauro que também é perceptível no "Varandas da Eva", é quanto sua precária condição financeira. Enquanto nesta obra o personagem deixa transparecer isso em uma de suas falas, em que afirma que Tarso é mais pobre que ele, em Cinzas do Norte podemos averiguar através do seguinte trecho: “[...] A roupa remendada do Minotauro, os dentões escuros e apodrecidos e o lugar onde morava - um barraco sem endereço no fundo do Buraco do Pinto - a impressionaram. [...]” (Ibidem, p. 71). Em relação aos dentes de Minotauro, também há menção disso no "Varandas da Eva”: “[...] Minotauro, tenebroso, mostrando dentes de cavalo. [...]” (HATOUM, 2014, p. 11). Assim, pelas confluências das características, em ambas as obras: corpanzil, dentes grandes, situação financeira desfavorável, valente e intimidador, sugerimos o reaproveitamento da personagem em ambos enredos.

Outro aspecto comum entre as obras, que desperta interesse, diz respeito à profissão dos narradores, pois no romance, o narrador Lavo trabalha advogando em favor “'[...] de detentos miseráveis esquecidos nos cárceres. [...]” (HATOUM, 2010, p. 211) e no conto há uma sugestão de que o narrador exerce também a advocacia, não na área criminal como Lavo, mas na civil: “[...] eu acabara de sair de uma vara cível [...]” (HATOUM, 2014, p. 12).

Tendo observado elementos comuns no conjunto da obra de Hatoum, particularmente na configuração das personagens do romance Cinzas do Norte e do conto "Varandas da Eva", passaremos a averiguar as relações temáticas entre o mesmo conto e a novela Órfãos do Eldorado. Nesta novela o narrador-personagem Arminto Cordovil apaixona-se por Dinaura, uma personagem envolvida em áurea 
misteriosa: “[...] Uma índia? Procurei a origem, nunca encontrei. [...]” (HATOUM, 2008, p. 15), pois não se sabe sob que circunstância veio morar no orfanato Sagrado Coração de Jesus. Outrossim, há um mistério em torno das relações entre a jovem e o pai de Arminto, Armando Cordovil, uma vez que, ao final do romance, o leitor fica com a interrogação se Dinaura era amante ou filha do velho Cordovil.

No conto, a relação entre o narrador e mulher do prostíbulo faz recordar ao leitor o elo que une Dinaura e Arminto. Aqui, como lá, o narrador se apaixona por uma mulher desconhecida, após uma única noite de amor: “[...] Meu nome? Tu não vais saber, é proibido, pecado. Meu nome é só meu. Prometo." (HATOUM, 2014, p. 10). Ademais, em ambas narrativas, a mulher some sem deixar evidências e o narrador, apaixonado, sofre a ausência: "Tia Mira dizia que eu estava babado de amor. Estás tonto por uma mulher, ela ria, observando meu devaneio triste, meu olhar ao léu." (HATOUM, 2014, p. 10). Há ainda que se salientar que em ambos os enredos fica a incógnita a identidade da mulher por quem o protagonista se enamora. Efetivamente, em "Varandas de Eva", lemos:

[...] Foi então que vi, numa canoa, um rosto conhecido. Era Tarso. Remou lentamente até
a margem e saltou; depois tirou um cesto da canoa e pôs o fardo nas costas, a alça em
volta da testa, como faz um índio. O corpo do meu amigo, curvado pelo peso, era o de
um homem. Subiu uma escadinha de madeira, deixou o cesto na porta de uma palafita,
voltou à margem e puxou a canoa até a areia enlameada. À porta apareceu uma mulher
para apanhar o cesto. Reapareceu em seguida e acenou para Tarso. Num relance, ela
ergueu a cabeça e me encontrou. Estremeci. Eu ia virar o rosto, mas não pude deixar de
encará-la. Ela me atraía, e a lembrança surgiu agitada, confusa. A voz dela chamou: meu
filho! A mesma voz, meiga e firme, da moça, da mulher da casinha vermelha, no balneário
Varandas da Eva. Era a mãe do meu amigo? [...] (HATOUM, 2014, p. 12)

Assim como no romance, portanto, o narrador finaliza a história com uma dúvida sobre a mulher a qual se apaixonou. No caso do conto, seria o amigo filho da mulher do Varandas? Isso explica o medo sentido por Tarso, que não o permitiu entrar no prostíbulo? Perguntas que não podem ser respondidas, assim como não podemos responder sobre a relação de Dinaura com Armando. Mas, como Dinaura e a prostituta inominada são descritas pelo narrador? Elas se parecem fisicamente?

A mulher incógnita do "Varandas da Eva" é descrita como possuidora de um sorriso encantador, voz meiga e firme, rosto belo, olhos acessos, na cor de fogo, comparado aos olhos de gata maracajá, e “[...] Não era alta, mas tinha um corpo cheio e recortado [...]” (HATOUM, 2014, p. 9). Mulher experiente na arte do prazer: "Ela me ensinou a fazer tudo, todos os carinhos, sem pressa, com o saber de uma mulher que já amou e foi amada. [...] Fez coisas que davam ciúmes, carícias que não se esquecem. [...]” (Ibidem, p. 10).

Já Dinaura é caracterizada como uma moça de meia idade, trabalhadeira e inteligente, rosto anguloso, lábios grandes, olhos pretos e puxados, olhar vivo: “[...] E Florita, sem conhecer a órfã, disse que o olhar dela era só feitiço: parecia uma dessas loucas que sonham em viver no fundo do rio." (HATOUM, 2008, p. 31). Em outra passagem notamos o poder do olhar de Dinaura: “[...] os homens 
iam atrás. Nenhum falava com a mulher. Por quê? Medo. Alguma coisa no seu olhar inibia mais que uma voz ou um gesto. Com medo, eram machos vencidos. [...]” (Ibidem, p. 37). Assim, percebemos que o olhar de Dinaura possui o poder de enfeitiçar.

Por ela não falar com as pessoas havia comentários de que ela era enfeitiçada por Jurupari, herói mítico e que era uma sucuri que iria levar Arminto para o fundo do rio. Era uma mulher entregue às lendas, que a envolviam em mistério.

Durante os poucos encontros com Arminto, ele percebeu que ora aparecia sorridente, ora triste, mas para ele "[...] Triste, ela era mais bonita [...]" (Ibidem, 41). Ela, também, revelava comportamentos, em relação a ele, contraditórios, pois em alguns momentos se aproximava com ímpeto, em outros, esquivava-se. Ele a considerou, certa vez, como índia e pobretona: “[...] meu pai tinha razão, eu era um aproveitador de índias e pobretonas. [...]” (Ibidem, p. 42), mas a verdade é que ela era sustentada pelo o pai dele, era uma órfã, do Sagrado Coração, mas que tinha regalias, morava só em uma casa atrás da igreja e recebia toda a assistência de Amando, de comidas a livros. Só depois de muitos anos é que Arminto ficou sabendo disso, inclusive da origem da moça: tinha nascido em uma ilha do rio Negro.

A partir dessas descrições, percebemos que nas características físicas essas mulheres não são descritas da mesma forma: enquanto uma arrebata pelo sorriso, a outra é pelo olhar e enquanto uma possui os olhos de gata maracajá a outra possui o olhar que é só feitiço. No entanto, essas duas mulheres se assemelham pela beleza, pelo o poder encantador, pela sensualidade e pelo o mistério que as envolvem. São mulheres que encantam pelo manejo sedutor, pois sabem, pretensiosa ou despretensiosamente, envolver os homens. Na relação, elas não se mostram por inteiro, fazendo com que o outro almeje descortiná-las, mas a cortina feminina apenas deixa brechas e espaços a serem revelados.

Este aspecto, cumpre observar, não é fortuito. Se na literatura de Hatoum ele comparece, é porque a mulher, como afirma Freud (1933), é o enigma por excelência. Com efeito, na psicanálise, a mulher foi alvo de anos de estudos, propiciados por inquietações que tinham o intuito de desvendar o feminino. Porém, mesmo após muita dedicação à busca da compreensão do feminino, o pai da psicanálise conclui que o feminino é indecifrável: “[...] a psicologia é incapaz de solucionar o enigma da feminilidade. [...]” (FREUD, 1933, p. 4621). A mulher se mostra como enigma insondável, pois a compreensão total não se completa. Assim se mostram Dinaura e a personagem sem-nome do conto. Dinaura se obscurece na sua mudez e a prostituta do "Varandas da Eva", por não falar seu nome encobre sua identidade.

É importante frisar que todos esses elementos destacados acima, referente às narrativas, são manifestados ao leitor por meio da recordação dos narradores. Nas três obras aqui analisadas, a representação da memória dos narradores é que conduz as tramas: memórias subjetivas que envolvem lembranças e esquecimentos, dando aos textos um teor verossímil, pois assim como ocorre no mundo real, a representação da memória na literatura é: 
[...] a tentativa de recompor imagens passadas: tentativa impossibilitada de resgatar o traço primeiro, a origem, de preencher o vazio. O seu processo de recomposição articularse-ia ao desvanecimento das imagens, instaurando, de forma dialética, a perda junto ao trabalho de construção. (RAMOS, 2011, p. 98).

A memória envolve imagens recuperadas e perdidas, que Hatoum tão bem articula em suas obras. Em Órfãos do Eldorado, o narrador revela o que conta: “[...] Conto o que a memória alcança, com paciência." (HATOUM, 2008, p. 15) e deixa o leitor perceber as lacunas inseridas na diegese, notadas pela maneira como expõe a falta de uma informação, atribuída à não lembrança: “[...] Não lembro do rosto dessa ama, de nenhum. Tempo de escuridão, sem memória. [...]” (Ibidem, p. 16). Em Cinzas do Norte podemos, já no título, inferir a presença da "memória", em que cinzas seriam os resquícios das experiências vividas pelo narrador, do que restou na memória, além de mostrar as ruínas de um tempo áureo: “[...] Lembro do Natal triste de 1960 [...]” (HATOUM, 2010, p. 20). Neste romance, percebemos uma memória que dá saltos no tempo, gerando uma narrativa não linear e ainda mais verossímil, pois na realidade, ou seja, no nosso cotidiano mental, as lembranças não surgem de maneira linear. No conto também notamos que o narrador revela momentos em que a memória traz lembranças claras: “[...] sinto ânsias só de lembrar.” (HATOUM, 2014, p. 10), a ponto de causar sensações como se tivesse revivendo o momento. Porém, há, também, momentos em que a memória não esclarece: “[...] a lembrança surgiu agitada, confusa. [...]” (Ibidem, p.12).

Em Cinzas do Norte, por sua vez, a sintaxe temporal ganha um diferencial, já que os percursos da memória são conduzidos por três narradores (Lavo, Ranulfo e Mundo) que expõem experiências pretéritas alternando narrações com diferentes pontos de vista. É o tempo sendo vivido conforme as lembranças de três personagens.

Assim, notamos que a memória tem um papel fundamental para a construção do enredo, nas três obras estudadas, já que os narradores falam de acontecimentos do passado. Tacca (1983, p. 128) argumenta que "[...] Todo o relato não é mais do que a límpida evocação do passado [...]”, que se encontra na memória e se concretiza por meio de recordações. O discurso memorialístico dos narradores resgata personagens e experiências semelhantes numa estruturação alinear, em que, como nos referimos anteriormente, a narração revela anacronias, regressos e avanços temporais, trazendo, às obras, o teor memorialístico, as quais possuem, apesar de semelhanças, estruturais cronológicas específicas que conduzem distinções entre elas.

\section{Considerações finais}


Após essa leitura atenta a essas três obras de Milton Hatoum, podemos sugerir um entrelaçamento de personagens, de narradores, de temática, bem como a importância da memória discursiva no desenvolvimento das tramas. O narrador do conto "Varandas da Eva" possui vários pontos de contato com o narrador da obra Cinzas do Norte, como parentes de mesmo nome, mudança de bairro e a mesma profissão. Já em relação ao narrador-personagem deste conto e o de Órfãos do Eldorado, ambos se assemelham no que concerne a situação vivida: a paixão por uma mulher misteriosa e a impossibilidade de reviver os prazeres experimentados. Tanto Dinaura quanto a mulher incógnita são desejadas e, apesar de almejadas, permanecem inalcançadas.

Quanto aos personagens de nomes Minotauro e Ranulfo, pudemos igualmente observar traços comuns. Nesse sentido, conclui-se haver na obra do Hatoum, pelo resgate da memória, o reaproveitamento de aspectos temáticos e/ou de personagens que ressurgem em sua obra.

\section{Referências}

AGUIAR E SILVA, Vitor Manuel de. Teoria da literatura 8ª ed. Coimbra: Almedina, 2011.

FREUD, Sigmund (1933). Feminilidade . Obras Completas. Tradução Luis Lopez-Ballesteros. $4^{\mathrm{a}}$ ed. Madrid: Biblioteca Nueva, 1981.

HATOUM, Milton. A cidade ilhada: contos. $1^{\text {a }}$ ed. São Paulo: Companhia das Letras, 2014.

Cinzas do Norte. São Paulo: Companhia das Letras, 2010.

Órfãos do Eldorado. São Paulo: Companhia das Letras, 2008.

NUNES, Benedito. O tempo na narrativa. $2^{a}$ edição. São Paulo: Ática, 1995.

RAMOS, Danielle Cristina Mendes Pereira. Memória e literatura: contribuições para um estudo dialógico. Linguagem em (Re)vista, Ano 06, Nos. 11/12. Niterói, 2011, p. 92-104. Disponível em http://www.filologia.org.br/linguagememrevista/1 1/07.pdf Acesso: 02/05/2016.

TACCA, Oscar. As vozes do romance. Trad. Margarida Coutinho Gouveia. $2^{\mathrm{a}}$ ed. Livraria Almedina. Coimbra: 1983. 